\title{
Pesquisa experimental sobre tipografia inclusiva para a terceira idade
}

\section{Experimental research on inclusive typography for the elderly}

\author{
Bruno Serviliano Santos Farias, UFMA \\ bruno.serviliano@ufma.br
}

Paula da Cruz Landim, UNESP

paula@faac.unesp.br

\begin{abstract}
Resumo
O envelhecimento populacional tenderá a se intensificar nos próximos 50 anos, exigindo da sociedade novas demandas e arranjos sociais. No Brasil, além do próprio processo de envelhecimento, que compromete as capacidades motoras, sensoriais e cognitivas, o idoso brasileiro tem baixa escolaridade. Por isso, as Universidades da Terceira Idade são tão populares no país. O design, imbuído de métodos inclusivos, pode propor novos artefatos acessíveis para essa nova realidade. Assim, o objetivo desse estudo é compreender a relação entre os elementos tipográficos e o processo de envelhecimento, em especial no desempenho da percepção e compreensão. O presente estudo apresenta uma pesquisa sobre tipografias inclusivas para a Terceira Idade. Através de métodos experimentais com 44 idosos em situação de ensino foi possível analisar as características mais adequadas para esse público. As possíveis hipóteses levantadas nessa pesquisa apontam para as seguintes articulações inclusivas: o estilo de traço com contraste mínimo e elementos de diferenciação.
\end{abstract}

Palavras-chave: design gráfico inclusivo, tipografia inclusiva, terceira idade

\begin{abstract}
Population aging tends to intensify in the next 50 years, requiring from society new demands and social arrangements. In Brazil, in addition to the aging process itself, which compromises motor, sensory and cognitive abilities, the Brazilian elderly have low levels of schooling. Therefore, the Third Age Universities are so popular in the country. The design, imbued with inclusive methods, can propose new artefacts accessible to this new reality. Thus, the aim of this study is to understand the relationship between typographic elements and the aging process, especially in the performance of perception and understanding. The present study presents research on inclusive typography for the elderly. Through experimental methods with 44 elderly people in a teaching situation, it was possible to analyze the most suitable characteristics for this audience. The possible hypotheses raised in this research point to the following inclusive articulations: the stroke style with minimal contrast and elements of differentiation.
\end{abstract}

Keywords: including graphic design, typography inclusive, elderly 


\section{Introdução}

O envelhecimento populacional foi um fenômeno observado ao longo do século XX e que deve se acentuar no século XXI. A ONU (2019) afirma que a tendência é que 1 em cada 6 pessoas terá 65 anos ou mais no mundo em 2050. O Brasil tem cerca de 30 milhões de idosos, representando cerca de $15 \%$ da população e vem crescendo mais rapidamente que a proporção de crianças (IBGE, 2018).

O país adota como critério para definição da pessoa idosa a idade de 60 anos, como consta no Estatuto do Idoso. De qualquer forma, algumas variáveis como acesso à saúde, alimentação, estilo de vida, podem antecipar ou retardar os efeitos da senilidade. A educação é uma das variáveis que mais impacta na qualidade de vida (Q.V.) do idoso. Mais da metade das pessoas entre 55 e 64 anos no país não tem ensino fundamental completo, segundo IBGE (2018).

Os programas "Universidade para Terceira Idade" (UnTIs) são exemplos de iniciativas para tentar minimizar os efeitos sociais do envelhecimento. Os projetos oferecem atividades práticas e teóricas nas áreas de cultura, saúde e ginástica com a finalidade de minimizar os efeitos negativos do envelhecimento, resgatar laços afetivos e a autoestima, bem como fornece informações para garantir uma boa qualidade de vida (CUBA, 2015).

O design pode atuar para garantir o acesso à educação inclusiva e equitativa, para tornar as instalações acessíveis e para fornecer treinamento aos professores no desenvolvimento de uma linguagem e estrutura acessível para a Terceira Idade a fim de garantir uma pedagogia centrada nas características dos alunos.

A presente pesquisa foca em materiais didáticos para a Terceira Idade. Nesse sentido, o artigo tem como objetivo analisar os elementos tipográficos e seus impactos em idosos em situação de ensino considerando o processo de envelhecimento.

\section{Conceitos sobre Design Gráfico Inclusivo}

A abordagem funcionalista do design, baseada na produção de produtos para um ser humano médio, foi amplamente criticada no Pós-guerra. Na década de 60 a Sociedade de Artes Industriais pregou a atuação do Design menos tecnicista e mais voltado às necessidades sociais. Na década de 70, Papanek defendeu uma agenda social com articulações tecnológicas e contexto social, intermediando valores tangíveis e intangíveis com aspirações coletivas e com valores humanistas inseridos nos métodos de design. Na década de 80 outras formas de pensamento e novos métodos foram valorizados, investigando o comportamento, o desejo e a necessidade do usuário. (NEVES, 2011; CURTIS, 2011; BÜRDECK, 2010).

Tais concepções sobre o usuário/sujeito/ser humano, no âmbito projetual, permitiu o surgimento de novas abordagens e modelos de análises, valorizando as competências físicas e a organização social.

\section{Modelo Fisiológico}

O envelhecimento pode ser compreendido como um processo complexo marcado por mudanças e pela redução significativa na capacidade funcional (motora, sensorial e cognitiva). Essas capacidades se 
alteram com a idade e estudá-las do pondo de vista fisiológico permite verificar os sinais de senilidade ao longo do tempo (CAMARANO E PASINATO, 2004).

Tal ponto de vista considera pessoas com deficiência ou incapacitados por suas restrições físicas e mentais, por isso se considera essas pessoas incompletas, afirmam Clarkson e Coleman (2015). Os principais requisitos para avaliar projetos nesse modelo advêm da Ergonomia, considerando o contexto de uso, analisando as demandas e capacidades impostas pelo produto ao usuário, avaliando os atributos físicos exigidos e verificando quem são os excluídos (CLARKSON et al (2003). Critérios como acuidade visual (A.V.), destreza, força física, capacidade de memorização, entre outros, são comumente utilizados nos projetos.

$\mathrm{Na}$ funcionalidade cognitiva, há a manipulação de símbolos regida por regras de acordo com a sintaxe. A tarefa de reconstrução envolve atividades como lembrar, processar, prestar atenção e tomar decisões (WILLIAM, DAVIDS; WILLIAMS, 2005). A maioria das atividades cognitivas atinge seu ápice entre 20 e 30 anos e tendem a se manter até os 50 ou 60 anos (CANCELA, 2008). Na Terceira Idade é comum o aumento do risco de doenças mentais que afetam a memória, o julgamento e o controle das emoções, ocasionando um déficit cognitivo em idosos como lentidão e perda de precisão (GURGEL; SISTO, 2010). A cognição nesse sentido é o esforço de dar sentido, interpretar. Por isso, algumas estratégias gráficas são importantes para a geração de sentido ou redução do esforço cognitivo como redundância e hierarquização da informação.

Na funcionalidade sensorial há o declínio da acuidade visual (A.V.) que se inicia aos 40 anos e provoca a diminuição da percepção e a dificuldade em se adaptar ao brilho, restringindo a sensação luminosa. A lente se torna opaca e menos elástica, representando menos luz e dificuldade para a percepção de cores (azuis e violetas) e de objetos próximos (CLARKSON et al, 2003). A perda do campo central e periférico da visão é um dos problemas enfrentados na Terceira Idade, em especial para quem sofre com diabetes, afirma Nine (2006). Sem esse sentido, ou com ele comprometido, atividades com o ambiente seriam mais lentas e imprecisas, comprometendo a sensação e o comportamento, gerando a sensação de textos quebrados ou borrados, provocando manchas escuras no campo de visão diminuindo o contraste de imagens.

\section{Modelo Social}

No modelo social, a deficiência é imposta por desenhos inadequados que não consideram a diversidade física e mental. A configuração da demanda é uma decisão do designer que pode reduzir as barreiras que tornam o sujeito independente ou dependente de outra pessoa para executar uma atividade através de um artefato (CLARKSON; COLEMAN, 2015).

Não se considera a deficiência como um problema individual, mas se transfere a responsabilidade para a sociedade. Por isso, a deficiência é resultado da interação promovida pela organização social. Assim, uma pessoa que possui uma lesão pode não experimentar a deficiência caso a sociedade garanta a diversidade projetual (MEDEIROS; DINIZ, 2004).

Um dos principais critérios sociais é a qualidade de vida (Q.V.). Ter uma boa qualidade de vida não é um atributo do indivíduo, mas do ambiente, afirmam Carneiro; Falcone (2016). Laffin (2013) comenta que um problema enfrentado pelos idosos é sua adaptação ao mundo contemporâneo devido à deficiência educacional. $\mathrm{O}$ acesso à escola no Brasil se ampliou tardiamente na década de 60, afirmam Dias; Farbiarz (2013). Nesse sentido, idosos no país têm baixa escolaridade. A adequação da linguagem visual é 
importante para produzir uma comunicação acessível e atingir um domínio amplo da leitura e da compreensão.

\section{Tipografia Inclusiva}

A Tipografia é a ciência que estuda as formas de comunicação verbal, considerando a estética e a legibilidade. A legibilidade estuda a expressão concisa das letras sem que elas sofram perdas quando lidas (FRUTIGER, 2007; LEEUW, 2010). Consoante Tinker (1963), a ótima legibilidade depende tanto da distinção entre as letras quanto da clareza na forma das palavras.

Leeuw (2010) afirma que as fontes podem melhorar o limiar perceptivo, reduzindo os ruídos de quem tem problemas de visão. Nesse sentido, a seleção e emprego das fontes tipográficas para artefatos gráficos utilizados para a Terceira Idade devem observar vários critérios. São eles, figura 1:

- Elementos de diferenciação: A altura-x, ascendentes, descendentes, abertura interna e o peso do traço poderiam contribuir para distinguir as letras e facilitar o reconhecimento das palavras. O conceito de simplificação das letras, que seria o conceito oposto dos elementos de diferenciação, poderia dificultar a distinção entre ela, como em caracteres geométricos (ARAÚJO, 2008; SOUSA, 2002; BRINGHURST, 2007, FARIAS; GUIMARÃES; MARQUES, 2018).

- Tamanho e altura-x: O tamanho da letra talvez seja a principal articulação tipográfica para melhorar a legibilidade. Letras muito pequenas dificultam a leitura. Com relação ao público idoso, as fontes com 14 pontos são mais rápidas e com menos erros de leitura do que as de 12 pontos. Letras maiores melhoram a percepção quando lidas isoladamente, mas não favorecem nem uma leitura rápida nem uma compreensão rápida. A velocidade de leitura e facilidade de percepção é influenciada pela altura-x pois parecerão mais ou menos largas (BURT et al, 1955; KITCHEL, 2018; SOUSA, 2002; BRAZ, HENRIQUES e DOMICIANO, 2017; BERNARD; LIAO; MILLS (2001).

- Tipo de traço: O contraste, ou modulação, é formado pela diferença da espessura entre as hastes podendo ser grande, médio ou nulo. Grandes modulações tendem a gerar ruídos de informação durante a leitura. Letras sem modulação tendem a gerar menos ruídos (SOUSA, 2002; BRINGHURST, 2007; NINE, 2006).

- Espaço interno das letras: O espaço em branco em uma página torna o texto mais legível por favorecer o contraste, incluindo entrelinhas e margem. O olho e a abertura também têm impactos na superfície impressa das letras. O contraste de letra ideal seria aquele que valorizasse tanto a espessura do traço quanto os espaços internos (KITCHEL, 2018; SOUSA, 2002; BRINGHURST, 2007). 


\section{凹罪|lij| ILijl |lij| Ilij| \\ Trebuchet}

Elemento de diferenciação

Figura 1: Articulações tipográficas

\section{Métodos e Técnicas}

O objetivo é avaliar o impacto dos elementos gráficos na percepção e compreensão de idosos em situação de ensino, considerando o processo de envelhecimento e suas questões fisiológicas e sociais. Para tal, a pesquisa foi organizada em duas etapas: pesquisa exploratória e pesquisa experimental. O presente artigo apresentará os dados preliminares da segunda pesquisa.

$\mathrm{Na}$ primeira fase foram mapeadas as instituições de ensino para Terceira Idade (48 UnTIs), analisadas suas atividades (539 disciplinas) e aplicado um questionário com professores e alunos dessas instituições (104 respondentes). Foram observadas que há várias dificuldades relacionadas aos alunos. As principais foram a escolaridade, saúde física e cognitiva. No entanto, o aspecto social é importante para os alunos na Terceira Idade. Eles declararam que procuram os programas para manter e desenvolver relacionamentos sociais e por isso passam mais de dois anos.

Os professores se esforçam para desenvolver materiais didáticos moldados às características da Terceira Idade, o que inclui a adequação da linguagem ao contexto desse público, com o uso de letras grandes e imagens para facilitar a leitura, por isso, é comum o desenvolvimento de materiais próprios. Porém, muitos docentes alegaram que não têm formação adequada para desenvolver materiais didáticos para a Terceira Idade. Assim, acabam usando apenas as fontes mais populares do pacote office, como Arial e Times New Roman.

Muitos alunos responderam que possuem algum problema de visão e citaram que as letras (75\%) e as imagens $(40 \%)$ nem sempre estão adequadas. Mesmo com esses problemas, eles mencionaram os materiais didáticos como importantes ferramentas para o ensino. Outros problemas gráficos também foram mencionados como: as impressões (cópia) dos materiais e o contraste das imagens. Metade afirmou que há vários problemas gráficos, como tamanho, qualidade de impressão, contraste e detalhes.

A segunda etapa foi a Pesquisa experimental. O presente estudo apresenta os dados iniciais da pesquisa coletada de 44 pessoas de 4 UnTIs. As etapas foram: apresentação do termo de consentimento, aplicação de testes fisiológicos e sociais e aplicação de testes tipográficos. 
O Termo de consentimento foi aprovado pelo Comitê de Ética da Unesp/Bauru com o número do parecer 2.518.873. O Mini Exame do Estado Mental (MEEM) avaliou a saúde mental e as competências cognitivas mais utilizadas de pessoas com indicativo de demência devido à breve e fácil aplicação, avaliando diversas funções cognitivas agrupadas em categorias. Tal teste utiliza dados quantitativos, variando de 0 a 30.

O Questionário sobre a Qualidade de Vida verificou quanto da vida é prejudicada pelo problema de visão e testou a responsividade e confiabilidade. Apesar de ter uma abordagem qualitativa emprega dados quantitativos, variando de 0 a 100. O teste de Snellen tem caráter quantitativo, variando de 0 a 1 , verificou quanto se perdeu da visão.

Para o teste tipográfico foram considerados os atributos da microestética tipográfica como tamanho, estilo, espaços internos e extensões com o intuito de verificar se tais atributos são significativos para a leitura de pessoas com problemas de visão na Terceira Idade.

Para a presente pesquisa foram selecionadas 6 fontes organizadas de acordo com os estilos do traço, contraste acentuado e com contraste mínimo. Como as fontes Arial e Times New Roman são as mais utilizadas pelos professores das UnTIs estas serão utilizadas como fontes bases para o estudo.

As demais fontes foram selecionadas a partir de um levantamento bibliográfico, tendo como referência fontes gratuitas dos pacotes Office, que são comumente empregadas pelos professores das UnTIs (BERNARD, LIAO e MILLS, 2001; FUJITA, 2004; NINE, 2006; CADENA, COUTINHO e ANDRADE, 2012; MEÜRER, GONÇALVES e CORREIO, 2014; SOARES, 2016; FARIAS, GUIMARÃES e MARQUES, 2018; KITCHEL, 2018; FARIAS E LANDIM, 2019). Em seguida foi desenvolvida uma tabela para escolher as fontes que apresentaram algumas características, como altura- $\mathrm{X}$, ascendentes, descendentes, abertura interna, o peso do traço e os elementos de diferenciação, conforme a tabela 1.

\begin{tabular}{|c|c|c|c|c|c|c|c|}
\hline & & 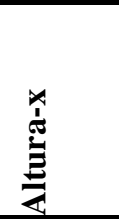 & 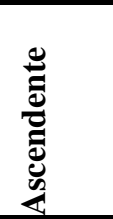 & 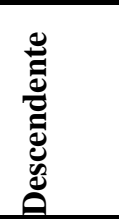 & $\frac{\pi}{3}$ & \& & 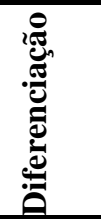 \\
\hline \multicolumn{8}{|c|}{ Contraste Mínimo } \\
\hline \multirow{4}{*}{$\mathbf{A}$} & Arial & - & - & Menor & - & - & Menor \\
\hline & Trebuchet & - & - & - & - & - & Maior \\
\hline & Gill Sans & Menor & Menor & Maior & Menor & Menor & - \\
\hline & Verdana & Maior & Maior & - & Maior & Maior & - \\
\hline \multirow{5}{*}{$\mathbf{A}$} & Contraste Ace & ituado & & & & & \\
\hline & Times N. R. & - & - & Menor & & & - \\
\hline & Bodoni & Menor & Menor & Maior & Menor & Menor & - \\
\hline & Book Antigua & - & - & Maior & Maior & Maior & - \\
\hline & Georgia & Maior & Maior & - & & - & - \\
\hline
\end{tabular}

Optou-se por escolher um destaque de cada categoria. Nesse sentido, as fontes selecionadas foram Arial, Trebuchet e Gill Sans para o estilo "contraste mínimo" e Times New Roman, Bodoni e Book Antigua para o estilo "contraste acentuado". 
Os testes avaliam letras, palavras e textos, com mudanças de tamanho das fontes, algo semelhante ao que ocorre no teste de Snellen. Para as letras e palavras os voluntários escreveram o que observaram. O registro da escrita permitiu verificar em quais momentos ocorrerem o erro de percepção. Para o texto, o voluntário leu em voz alta o que observou. As mudanças do ritmo de leitura foram consideradas como dificuldades de percepção e tabuladas como erro.

Para garantir a equivalência do esforço perceptivo e cognitivo foi necessário para cada grupo de letras e palavras que fossem empregadas a mesma quantidade de caracteres: 4 para as letras e 7 para as palavras. No texto foi empregado o mesmo autor, Fernando Pessoa, que trabalhou a métrica de cada estrofe. Desse modo, cada bloco de texto possui entre 19 e 21 palavras e entre 77 e 80 caracteres sem espaço. O intuito foi verificar quais articulações tipográficas são mais pertinentes na percepção e compreensão verbal.

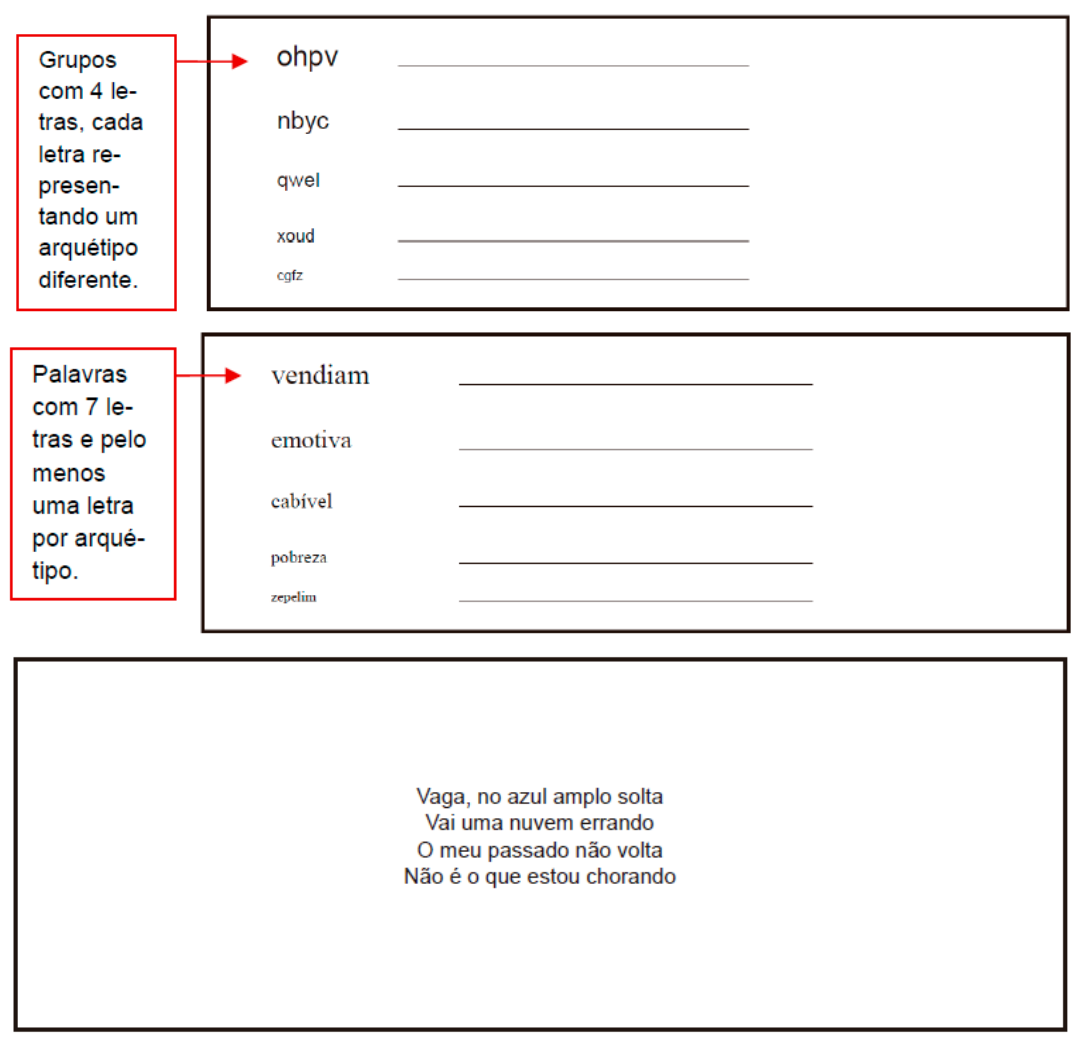

Figura 2: Teste tipográfico

Outra forma de garantir a equivalência do esforço perceptivo e cognitivo foi a utilização da variabilidade formal dos caracteres. Para tal, foi adotado o Gráfico de Derivação dos Arquétipos de Buggy (2007), figuras 3, o qual define que os grupos de caracteres podem ser desdobrados de 4 caracteres básicos: circulares derivado do "o", os verticais derivados do " $h$ " e do " $p$ ", incluindo os ascendentes e descendentes, e por último os traços oblíquos derivados do "v". Assim, nos testes de caracteres e palavras há pelo menos uma letra com arquétipo circular, uma com arquétipo vertical e um com arquétipo oblíquo. 


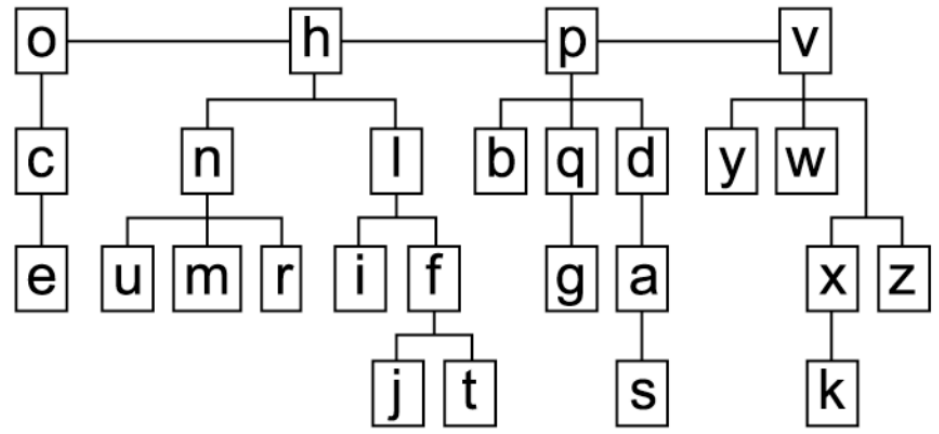

Figura 3: Arquétipos tipográficos

\section{Resultados}

A coleta de dados ocorreu em quatro instituições: na Universidade da Terceira Idade da UNESP de Bauru e de São José dos Campos, na Federal de Uberlândia e na Federal do Maranhão entre segundo semestre de 2018 e primeiro semestre de 2019. A seleção dessas instituições se deu pelo aceite para realização da pesquisa. Os dados brutos, tabela 2:

\begin{tabular}{rcccc}
\hline & Idade & MEEN & A.V. & Q.V \\
\hline Mínimo & 54 & 19 & 0,3 & 45 \\
\hline Máximo & 91 & 30 & 1,0 & 97 \\
\hline Média Aritmética & 66.8 & 25,7 & 0,83 & 82,2 \\
\hline Desvio Padrão & 7.7 & 2,4 & 0,23 & 9,8 \\
\hline \multicolumn{4}{r}{ Tabela 2: } \\
\hline \multicolumn{4}{l}{ Média dos dados sociais }
\end{tabular}

Sobre a A.V., $90 \%$ afirmaram ter algum problema de visão, mas $40 \%$ não souberam identificar o problema, $11 \%$ afirmaram ter catarata e o mesmo percentual afirmou ter astigmatismo, $9 \%$ miopia e $6 \%$ glaucoma. Sobre a escolaridade, 34\% afirmaram ter ensino superior completo ou incompleto, metade ter ensino médio completo ou incompleto e $16 \%$ ensino básico.

Relacionando a idade com as médias de dados das variáveis Desempenho Cognitivo (MEEN), A.V., incidência de Erros e de Tempo (em segundos) dos testes tipográficos tem-se, tabela 3:

\begin{tabular}{rccccc}
\hline Grupo Etário & MEEM & A.V & Q.V. & Erros & Tempo \\
\hline $\mathbf{6 6 9}$ & 25.39 & 0.87 & 80.39 & 6.16 & 36.00 \\
\hline $\mathbf{7 0 - 7 9}$ & 26.50 & 0.72 & 80.00 & 6.00 & 31.49 \\
\hline $\mathbf{8 0 - 8 9}$ & 26.33 & 0.73 & 87.33 & 2.67 & 50.06 \\
\hline $\mathbf{9 0 - 9 9}$ & 25.00 & 0.60 & 96.00 & 18.00 & 50.67 \\
\hline Geral & $\mathbf{2 5 . 6 0}$ & $\mathbf{0 . 8 3}$ & $\mathbf{8 1 . 1 9}$ & $\mathbf{6 . 1 7}$ & $\mathbf{3 6 . 6 9}$ \\
\hline
\end{tabular}

Tabela 3: Comparação de grupos etários com outras variáveis

Era de se esperar que a acuidade visual diminuísse com a idade, resultado do efeito do processo do envelhecimento. No entanto, a qualidade de vida também deveria apresentar a mesma tendência, o que não ocorre. Pode-se levantar a hipótese de que a Q.V. é uma categoria complexa na qual incidem outras variáveis, não apenas fisiológicas, mas talvez sociais, como renda, escolaridade, acesso à saúde. As 
demais categorias de análise, MEEM, erros e tempo, não apresentaram uma tendência linear. Há várias hipóteses que podem ser levantadas: o critério Idade não é a variável que melhor explica o processo de envelhecimento, a amostra não é significativa ou há outra variável incidindo sobre tais questões.

Relacionando a escolaridade com as médias das demais variáveis, tem-se, tabela 4:

\begin{tabular}{rccccc}
\hline Escolaridade & MEEM & A.V & Q.V & Erros & Tempo \\
\hline Básico & 22.83 & 0.87 & 74.17 & 12.00 & 62.56 \\
\hline Médio & 25.55 & 0.79 & 81.64 & 7.45 & 34.26 \\
\hline Superior & 26.80 & 0.88 & 83.33 & 2.73 & 29.92 \\
\hline Geral & $\mathbf{2 5 . 6 0}$ & $\mathbf{0 . 8 3}$ & $\mathbf{8 1 . 1 9}$ & $\mathbf{6 . 1 7}$ & $\mathbf{3 6 . 6 9}$ \\
\hline \multicolumn{7}{c}{ Tabela 4: Comparação da escolaridade com outras variáveis }
\end{tabular}

Ao contrário da idade, a escolaridade explica melhor o comportamento dos dados de forma linear. Quanto maior a escolaridade maior também o desempenho cognitivo e a percepção sobre a Q.V. e menor a média de erros e a média de tempo nos testes tipográficos. Na literatura da área de saúde há o fenômeno de reserva cognitiva que explica desempenho de idosos com maior grau de instrução. Quem tem maior escolaridade, mesmo sofrendo com os efeitos mais severos do processo de envelhecimento, tem maior probabilidade de desenvolver estratégias que compensam os efeitos negativos da senilidade.

Ao final de cada teste tipográfico (letra, palavra e texto) foi perguntado qual a preferência do estilo e o motivo da preferência. O resultado está na tabela a seguir, tabela 5:

\begin{tabular}{rcc}
\hline Preferências & Acentuado & Mínimo \\
\hline Legibilidade & 13 & 31 \\
\hline Subjetividade & 6 & 8 \\
\hline Tamanho & 5 & 30 \\
\hline Total & $\mathbf{2 4}$ & $\mathbf{6 9}$ \\
\hline Tabela 5: Preferência das fontes por categorias
\end{tabular}

Critérios objetivos, como "legibilidade" e "tamanho", foram as categorias mais citadas. A categoria "legível" foi citada como de fácil visualização. A categoria "subjetividade" foi citada em fontes consideradas familiares ou por ter uma estética bonita. A categoria "tamanho" foi citada como de maior escala. O estilo com maior preferência é o “contraste mínimo” por atender essencialmente critérios objetivos.

Analisando os dados das fontes tipográficas tem-se que, tabela 6:

\begin{tabular}{|c|c|c|c|c|}
\hline & Fontes & Erros & Eficiência (tempo) & Eficiência (caractere) \\
\hline \multirow{3}{*}{$\mathbf{A}$} & Trebuchet & 0,5 & 77,60 & 6,17 \\
\hline & Gill Sans & 0,8 & 48,63 & 4,44 \\
\hline & Arial & 1,0 & 36,50 & 3,53 \\
\hline \multirow{3}{*}{$\mathbf{A}$} & Book Antigua & 1,2 & 31,58 & 2,73 \\
\hline & Times New Roman & 1,4 & 29,21 & 2,47 \\
\hline & Bodoni & 1,5 & 27,33 & 2,26 \\
\hline
\end{tabular}

Tabela 6: Média de erros e eficiência por fontes

A fonte Trebuchet é a fonte com melhor eficiência. Para que tivesse um erro precisaria de 77,6 segundos ou 6,17 caracteres. Tal fato pode ser explicado pela característica da fonte, dentre as selecionadas para o estudo é a que apresenta maiores elementos de diferenciação, permitindo que mesmo 
errando seja possível corrigir, figura 4. Nota-se que as três fontes mais eficientes são do grupo "contraste mínimo", indicando que o estilo tem impacto significativo na percepção e compreensão.

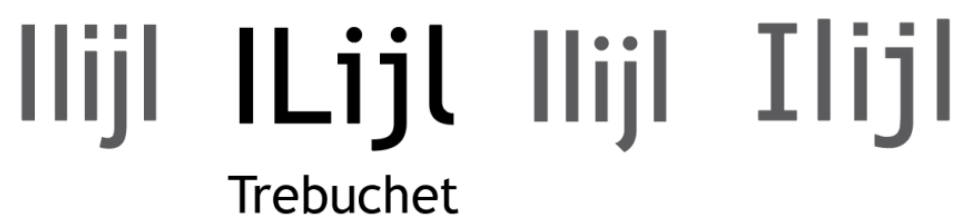

Figura 4: Fonte Trebuchet e os elementos de diferenciação

Por outro lado, a Bodoni é a fonte que apresenta menor altura-x, menor abertura e menor peso (figura 5), indicando que tais articulações tipográficas têm um efeito na incidência de erros e no tempo.

\section{ohpv ohpv \\ Bodoni \\ Gill Sans}

Figura 5: Comparações entre as articulações tipográficas

Sobre a incidência de erros tipográficos foi possível observar que, tabela 7:

\begin{tabular}{rccc}
\hline & Acentuado & Mínimo & Total \\
\hline $\mathrm{c} / \mathrm{e}$ & 23 & 4 & 27 \\
\hline $\mathrm{c} / \mathrm{o}$ & 1 & 6 & 7 \\
\hline $\mathrm{e} / \mathrm{c}$ & 5 & 1 & 6 \\
\hline $\mathrm{z} / \mathrm{s}$ & 0 & 3 & 3 \\
\hline $\mathrm{z} / \mathrm{x}$ & 2 & 0 & 2 \\
\hline $\mathrm{i} / \mathrm{l}$ & 0 & 2 & 2 \\
\hline $\mathrm{o} / \mathrm{a}$ & 2 & 0 & 2 \\
\hline deveras & 15 & 2 & 17 \\
\hline entreter & 11 & 2 & 13 \\
\hline choro & 8 & 0 & 8 \\
\hline comboio & 7 & 1 & 8 \\
\hline errando & 1 & 6 & 7 \\
\hline cessar & 1 & 5 & 6 \\
\hline fingidor & 5 & 0 & 5 \\
\hline solta & 1 & 3 & 4 \\
\hline ajusto & 1 & 3 & 4 \\
\hline a & 4 & 0 & 4
\end{tabular}

Tabela 7: Incidência de erros por caracteres e palavras

A maior incidência de erros está em caracteres derivados de arquétipos circulares como em "e", "o", “c”, possivelmente a simplificação da forma contribui para aumentar a incidência de erros. Além disso, a maior incidência de erros está no estilo "contraste acentuado". Possivelmente o estilo do traço "contraste mínimo”, que propicia maior área de impressão, melhora a visibilidade das letras. A área de impressão pode ser uma articulação tipográfica que incide na redução/aumento da incidência de erros.

Diante de todos esses dados levantam-se as seguintes hipóteses: categorias sociais, como escolaridade, tem maior impacto na percepção e compreensão de letras e palavras do que categorias fisiológicas; a seleção de 
fontes por critérios objetivos, como tamanho e legibilidade, por um estilo com "contraste mínimo" e elementos de diferenciação impactariam no desenvolvimento de artefatos gráficos inclusivos para Terceira Idade, reduzindo o tempo e a incidência de erros.

\section{Consideração Final}

Para compreender o impacto da linguagem verbal nos materiais didáticos de idosos em situação de ensino foi realizada uma pesquisa experimental com 44 alunos das UNTIs. A pesquisa observou que a grande maioria dos idosos tem algum problema de visão, metade possui ensino médio e um terço ensino superior. A educação foi a categoria que melhor explicou os fenômenos observados, tanto sobre a Q.V., quanto nas questões gráficas.

Sobre as fontes, os dados reforçam a hipótese que há um conjunto de características que tornam uma fonte inclusiva. Tanto na preferência, quanto no tempo, na incidência de erros e na eficiência o estilo com “contraste mínimo" seria o mais inclusivo por possuir maior altura-x, mais elementos de diferenciação e terem traços mais visíveis. Além disso, arquétipos circulares apresentaram maior incidência de erros, o que indica uma maior atenção nesses caracteres para gerar distinção entre eles. Contudo, o presente estudo apresenta dados preliminares que serão confrontados com os dados completos.

O presente trabalho foi realizado com apoio da Coordenação de Aperfeiçoamento de Pessoal de Nível Superior - Brasil (CAPES) - Código de Financiamento 001.

\section{Referências}

ARAÚJO, Emanuel. A construção do livro: princípios da técnica de editoração. Rio de Janeiro: Lexikon, 2008.

BERNARD, Michael; LIAO, Chia Hui; MILLS, Melissa. The effects off on type and size on the legibility and reading time of online text by older adults. Chi '01 Extended Abstracts On Human Factors In Computing Systems - Chi '01, [s.1.], p.175-176, 2001. ACM Press. http://dx.doi.org/10.1145/634067.634173. Disponível em: https://dl.acm.org/citation.cfm?id=634173. Acesso em: 27 maio 2017.

BRAZ, Matheus Petroni; HENRIQUES, Fernanda; DOMICIANO, Cassia Letícia Carrara. Design sem barreiras: Discussão-ação em Design Gráfico Inclusivo. In: ANDRADE, Ana Beatriz Pereira de et al. Ensaios em Design: Saberes e processos. Bauru: Canal 6, 2017. p. 161-199.

BRINGHURST, Robert. Elementos do estilo tipográfico. São Paulo: Martins Fontes, 2007.

BUGGY. O MECOTipo: método de ensino e desenho coletivo de caracteres tipográficos. Olinda: Tipos do Acaso, 2007.

BÜRDECK, Bernhard E. História, teoria e prática do design de produtos. São Paulo: Blücher, 2010.

BURT et al. A psychological study of typography. The British Journal of Statistical Psychology. 1955. p. 29-65.

CADENA, Renata A.; COUTINHO, Solange G.; ANDRADE, Bruna. A linguagem gráfica em artefatos educacionais gerados com ferramentas de TIC. Infodeign, [s.i], v. 1, n. 9, p.3344, 2012. 
CAMARANO, Ana Amélia; PASINATO, Maria Tereza. O envelhecimento populacional na agenda das políticas públicas. In: CAMARANO, Ana Amélia (Org.). Os novos idosos brasileiros: muito além dos 60?. Rio de Janeiro: Ipea, 2004. p. 253-292.

CANCELA, Diana Manuela Gomes. O processo de envelhecimento. Psicologia, Porto, p.115, 16 maio 2008. Disponível em: http://www.psicologia.pt/artigos/textos/TL0097.pdf. Acesso em: 27 maio 2018.

CARNEIRO, Rachel Shimba; FALCONE, Eliane Falcone. Avaliação de um programa de promoção de habilidades sociais para idosos. Análise Psicológica, [s.1.], v. 34, n. 3, p.279291, 12 set. 2016. ISPA - Instituto Universitário. Disponível em: http://publicacoes.ispa.pt/index.php/ap/article/view/960/pdf. Acesso em: 27 maio 2018.

CLARKSON, P. John; COLEMAN, Roger. Historyof Inclusive Design in the UK. AppliedErgonomics, [s.1.], v. 46, p.235-247, jan. 2015. Elsevier BV. Disponível em: https://www.sciencedirect.com/science/article/pii/S0003687013000410. Acesso em: 27 maio 2018.

CLARKSON, John et al. Inclusive Design: design for the whole population. 2. ed. London: Springer-verlag, 2003. $611 \mathrm{p}$.

CUBA, Conceição de Mara G. Braga. Guarnicê e cidadania na amizade dos idosos cariocas e ludovicenses. São Luis: Edufma, 2015.

CURTIS, Maria do Carmo. A dimensão social do design gráfico no contrustivismo. In: BRAGA, Marcos da Costa (Org.). O papel social do design gráfico: História, conceitos e atuação profissional. São Paulo: Senac São Paulo, 2011. p. 25-44.

DIAS, Cynthia Macedo; FARBIARZ, Jackeline Lima. Livro didático: palavra, imagem e ação. Nós do ensino: perspectivas interdisciplinares de leituras do design. Rio de Janeiro: $2 \mathrm{AB}, 2013$.

FARIAS, Bruno Serviliano Santos; GUIMARÃES, Márcio James; MARQUES, Arthur José Silva. TIPOGRAFIA INCLUSIVA: proposta de análise de elementos tipográficos em materiais didáticos para a terceira idade. Anais do $8^{\mathbf{0}}$ Congresso Internacional de Design da Informação / $8^{\circ}$ Congresso Nacional de Iniciação Científica em Design da Informação, Natal, p.462-474, abr. 2018. Editora Blucher. Disponível em: https://www.proceedings.blucher.com.br/article-details/tipografia-inclusiva-proposta-deanlise-de-elementos-tipogrficos-em-materiais-didticos-para-a-terceira-idade-28028. Acesso em: 27 out. 2018.

FARIAS, Bruno Serviliano Santos; LANDIM, Paula da Cruz. Legibilidade para a Terceira Idade. Anais do $13^{\circ}$ Congresso Brasileiro de Pesquisa e Desenvolvimento em Design, Joinville, 2019.

FRUTIGER, Adrian. Sinais e símbolos. São Paulo: Martins Fontes, 2007.

FUJITA, Patrícia Tiemi Lopes. A comunicação visual de bulas de remédios: análise ergonômica da diagramação e forma tipográfica com pessoas de terceira idade. Infodesign, [s.n], v. 1, n. 1, p.51-54, 2004. Disponível em: https://www.infodesign. org.br/infodesign/article/view/3. Acesso em: 1 maio 2018.

GURGEL, Marina Gasparoto do Amaral e SISTO, Fermino Fernandes. Estudo correlacional entre inteligência e memória em idosos. Aval. psicol. [online]. 2010, vol.9, n.2, pp. 163-172. Disponível em: http://pepsic.bvsalud.org/scielo.php?script=sci_arttext\&pid=S167704712010000200003. Acessado em: 11 de dez. 2017.

IBGE. Síntese de indicadores sociais: uma análise das condições de vida da população brasileira. Rio de Janeiro: IBGE, 2018.

KITCHEL, J. Elaine. APH Guidelines for Print Document Design. APH. 2018. Disponível em: http://www.aph.org/research/design-guidelines/. Acesso em: 14 de dez. 2018. 
LAFFIN, Maria Hermínia Lage Fernandes. Alfabetização de idosos e adultos ou leitura e escrita? Revista Portuguesa de Educação, [s.1.], v. 25, n. 2, p.141-165, 30 set. 2013. University of Minho. http://dx.doi.org/10.21814/rpe.3005. Disponível em: https://revistas.rcaap.pt/rpe/article/view/3005. Acesso em: 27 out. 2018.

LEEUW, Renske de. SpecialFont For Dyslexia?. Dissertação (Mestrado em Psicologia). University of Twente. Enschede, 2010.

MEDEIROS, Marcelo, DINIZ, Debora. Envelhecimento e Deficiência. In: CAMARANO, Ana Amélia (Org.). Os novos idosos brasileiros: muito além dos 60?. Rio de Janeiro: Ipea, 2004. p. 107-120.

MEÜRER, Mary Vonni; GONÇALVES, Berenice Santos; CORREIO, Vilson João Batista. Tipografia e baixa visão: uma discussão sobre a legibilidade. Projética. Londrina, V.5 N.2, p. 33 - 46, dezembro. 2014.

NEVES, Flávia de Barros. Contestação gráfica: engajamento político-social por meio do design gráfico. In: BRAGA, Marcos da Costa (Org.). O papel social do design gráfico: História, conceitos e atuação profissional. São Paulo: Senac São Paulo, 2011. p. 4564.

NINE, Paul. Typography and the aging eye: typeface legibility for older viewers with vision problems. Aiga, 2006 Disponível em: http://www.aiga.org/typography-and-the-aging-eye, Acesso em: 30 abr. 2017.

ONU. World Population Prospects 2019: Highlights. Nova Iorque, 2019. Disponível em: https://population.un.org/wpp/Publications/Files/WPP2019_Highlights.pdf, Acesso em: 17 jun. 2019.

SOARES, João Marcelo Ribeiro. Design gráfico ergonômico: método para verificação de níveis de usabilidade de fontes tipográficas para texto em suportes 119 impressos e digitais. 2016. Tese (Doutorado em Design) - Universidade Estadual Paulista. Faculdade de Arquitetura, Artes e Comunicação, Bauru, 2016.

SOUSA, Miguel. Guia de Tipos: Métodos para o uso das Fontes de PC. Estugarda, 2002.

TINKER, Miles A. Legibilityof print. Ames: Iowa State University Press, 1963.

WILLIAM, A. M.; DAVIDS, K. WILLIAMS, J. G. Visual Perception and action in sport. Londres: EeFNSpon, 2005.

\section{Sobre o autor}

Bruno Serviliano Santos Farias

Doutor em Design pela UNESP-BAURU. Mestre em Design pela UFMA. Professor do Departamento de Desenho e Tecnologia da Universidade Federal do Maranhão. Tem como foco de pesquisa Design Gráfico Inclusivo e Artefatos Interativos. E-mail: bruno.serviliano@ufma.br

\section{Paula da Cruz Landim}

Mestre em Geografia pelo Instituto de Geociências e Ciências Exatas da Universidade Estadual Paulista, UNESP, Doutora em Arquitetura e Urbanismo pela Faculdade de Arquitetura e Urbanismo da Universidade de São Paulo FAU - USP. Professora do Departamento de Design da Faculdade de Arquitetura, Artes e Comunicação - FAAC da UNESP. Atualmente pesquisa Desenho do Objeto, Projeto de Mobiliário, História do Design e Teoria e Crítica do Design. E-mail: paula@ faac.unesp.br 